boar. These two aspects are dealt with successively. The compared characteristics of six pig breeds (Large White, French Landrace, Belgian Landrace, Piétrain, Hampshire and Duroc) are analysed, both for boar reproductive performance (libido, feed and leg soundness, stress susceptibility, fertility, effect on litter size) and for growth and carcass traits of crossbred progeny. The results of the ten-year I.N.R.A. programme on the evaluation of pig sire lines are presented and discussed, particularly in terms of lean tissue growth rate and lean tissue food conversion in crossbred pigs sired by boars from these six breeds.

An overall analysis of all traits considered, shows that at the present time, several genetic types of terminal boars following different routes give similar results. In most cases, use of a «specialized» boar line prevails over backcrossing and the trend of progressive decline of backcrossing in France seems to be justified. Among the «specialized 》 sire breeds, Belgian Landrace and Hampshire are the highest ranking breeds for lean tissue growth rate and lean tissue food conversion in crossbred offspring : these two breeds have a major part to play, for instance as a crossbred Hampshire $\times$ Belgian Landrace, boar. Taking into account the unfavourable influence of Hampshire on meat quality and the advantage of Large White as regards boar reproductive efficiency, the Belgian Landrace $\times$ Large White combination is another interesting boar choice for terminal crossing.

IV. - FEEDING

\title{
Utilization of cereals in simple feeds for weaned piglets Comparison between maize, wheat and barley
}

\author{
J. FEKETE *, J. CASTAING **, O. LAVOREL *, M. LEUILLET * \\ * I.T.C.F., 8, avenue du Président-Wilson, F 75116 Paris \\ ** A.G.P.M., 122, boulevard Tourasse, F 64000 Pau
}

Four trials were made in the same conditions and in two experimental stations to compare different lots of cereals : Maize - Wheat - two and six-row Barley.

The experimental feeds included a minimum of $3.5 \mathrm{~g}$ lysine per $1000 \mathrm{~kg}$ digestible energy by combining a cereal, soybean-oil meal and a vitamin-mineral mixture.

The levels of incorporation of the cereals varied from 54 to 66 p. 100 and those of the soybean meal « $50 »$ from 29 to 37 p. 100 .

Piglets were weaned at a mean age of 26 days (mean weight $6.4 \mathrm{~kg}$ ) whereafter the experimental groups were formed taking into account the weight at weaning and the mean litter weight at birth. They were housed in groups of 6 or 7 animals per box in isolated warmed and ventilated post-weaning rooms (flat-deck). They were fed for two weeks the first age diet (pellets) already used before weaning, then for 28 or 35 days one of the experimental diets (pellets) ad libitum. A total of 2592 piglets were used, i.e. 405 to 771 animals per diet.

Simple diets composed of cereals and soybean meal allowed to obtain high performances when used in weaned piglets between $8-10$ and $25-27 \mathrm{~kg}$ (feed intake 920 to $1080 \mathrm{~g} / \mathrm{d}$, growth : 500 to $570 \mathrm{~g} / \mathrm{d}$ ).

Piglets tended to consume all the more as diets were less energetic. This resulted in a spontaneous adjustment to the consumption expressed in digestible energy. As regards the growth rate, comparisons between the various groups of cereals did not indicate differences superior to $2 \mathrm{p}$. 100 . Feed conversion ratios regularly increased from the feeds based on maize to those based on six-row barley together with a reduction in the energy concentration of the diets, the discrepancies being often significant. According to the energy conversion ratios expressed in kcal digestible energy per $\mathrm{kg}$ live weight gain, the two barley varieties were often ranked first. 